\title{
Medicare for All: Considerations for Neuroradiologists
}

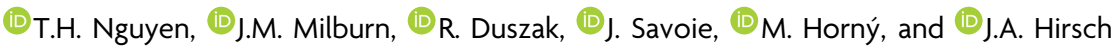

\section{ABSTRACT}

SUMMARY: The year 2019 featured extensive debates on transforming the United States multipayer health care system into a singlepayer system. At a time when reimbursement structures are in flux and potential changes in government may affect health care, it is important for neuroradiologists to remain informed on how emerging policies may impact their practices. The purpose of this article is to examine potential ramifications for neuroradiologist reimbursement with the Medicare for All legislative proposals. An institutionspecific analysis is presented to illustrate general Medicare for All principles in discussing issues applicable to practices nationwide.

ABBREVIATIONS: MFA = Medicare for All; PC = professional component

S enator Bernie Sanders originally introduced the Medicare for All (MFA) Act in 2017, which aimed to establish a single national health insurance program. At that time, the bill was supported by only 16 other senators and eventually died in the 115th Congress. Fast forward 2 years: Several 2020 presidential candidates now emphatically endorse MFA, aligned with the fact that during the past decade, the support by the public for a national health plan has grown. ${ }^{1}$ In April 2019, Senator Sanders reintroduced his MFA bill with expanded covered services. ${ }^{2}$ This came on the heels of an additional MFA bill proposed in the House of Representatives in February 2019 by Representative Pramila Jayapal. ${ }^{3}$ Other politicians have proposed offering public health insurance while preserving private options. ${ }^{4}$ With health care reform at the center of national debate during this election year, it is important for physicians to be abreast of potential landmark health care legislation. While varying plans have been proposed on how to reform US health care, only the 2 aforementioned MFA Acts have been formally introduced in Congress at the time of this writing. The fundamental objectives common to both bills are summarized in Table 1. In this article, we use the term "MFA" specifically in reference to both Medicare for All Acts of 2019.

Received January 16, 2020; accepted after revision March 7.

From the Department of Radiology (T.H.N., J.M.), Ochsner Health System, New Orleans, Louisiana; Department of Radiology and Imaging Sciences (R.D., M.H.), Emory University School of Medicine, Atlanta, Georgia; Imaging Services Administration (J.S.), University of Southern California Keck School of Medicine, Los Angeles, California; Department of Health Policy and Management (M.H.), Emory University Rollins School of Public Health, Atlanta, Georgia; and Department of Radiology (J.A.H.), Massachusetts General Hospital, Boston, Massachusetts.

Please address correspondence to Theresa H. Nguyen, MD, Department of Radiology, Ochsner Health System, 1514 Jefferson Hwy, New Orleans, LA, 70121; e-mail: Theresa.Nguyen@ochsner.org; @TheNguyenMD

http://dx.doi.org/10.3174/ajnr.A6524
The financial impact of MFA implementation on individual radiology practices would depend on the case mix of services of each practice, the payer mix for each patient service, and reimbursement rates currently negotiated with private payers. The current payment models of the practice (eg, fee-for-service, bundled payments, or global budget) are also determinants of the potential impact of MFA on that particular practice. The MFA bills do not specifically address payment models; therefore, it is unclear how these would be affected. Thus, it is uncertain what would happen with reimbursement penalties and bonuses under the Merit-Based Incentive Payment System and Medicare Access and CHIP Reauthorization Act of 2015.

The ambiguity in MFA makes it difficult to predict the effect of MFA on a practice. However, the salient feature in the MFA legislative proposals is essentially transitioning the US multipayer health care system to a single-payer system. The goal of this Practice Perspectives is to discuss issues neuroradiologists may encounter in such a transition. We also provide an institution-specific analysis to illustrate the degree of impact this shift can have on a practice. The analysis is based on the case mix of the primary author's institution and reimbursement figures for its locale. Medicare global, professional component (PC), and technical component fees were determined using the Medicare Physician Fee Schedule for $2019 .^{5}$ Private reimbursement rates for noncapitated services provided by in-network providers to patients with primary residence in Louisiana or Mississippi (the Data Use Agreement prohibited us from reporting state-level metrics for Louisiana only) were extracted from the IBM MarketScan Commercial Claims and Encounters Database for the year 2017. All payments were adjusted for inflation using the seasonally-adjusted Consumer Price Index for Medical Care obtained from the Federal Reserve 
Bank of St. Louis and expressed in 2019 US dollars. ${ }^{6}$ Medicaid fees in this study represent hospital-based Medicaid PC fee averages in Louisiana for the respective examinations and were provided by the radiology finance department of our lead study site. Although the analysis is institution-specific, it serves as a realworld example to illustrate general issues that apply to practices nationwide.

\section{Financial Implications for Providers}

In the United States, approximately $49 \%$ of the general population receives health insurance through their employers; $20 \%$, through Medicaid; and 14\%, through Medicare. About $9 \%$ of the population is uninsured. Other coverage comprises individual/ nongroup insurance $(6 \%)$ and military $(1 \%){ }^{7}$ Under MFA, private health insurers would be prohibited from offering benefits included in the public program. The transition from a multipayer to single-payer system could have negative financial consequences for many radiologists because private insurer fees typically exceed those of Medicare. ${ }^{8,9}$ With regard to neuroradiology, brain MR imaging payments from private insurers were shown to be more than twice as high as Medicare fee-for-service payments in a 2018 study published by the Congressional Budget Office. ${ }^{8}$

The difference between Medicare and private insurance fees is affected by factors including the negotiating power of a practice with private insurers, case mix, and the Geographic Practice Cost Index. As an example of variation between Medicare and private insurance reimbursement for a neuroradiology practice, Table 2 shows a brain examination case mix from the primary author's radiology department with fees from Medicare and estimated average reimbursements from private insurers.

The shift to MFA could be especially disruptive for practices that currently treat a large portion of privately insured patients because private insurer fees are typically higher than those of Medicare throughout the country. ${ }^{8-10}$ Conversely, MFA could increase revenue for some practices by reducing their uncompensated care for uninsured patients as well as by increasing their reimbursement for care of patients currently covered by lower-paying Medicaid. ${ }^{11}$ Previous research found the average national Medicaid-to-Medicare fee index is $0.72,{ }^{12}$ though inpatient Medicaid fees vary on the basis of specific hospital cost-to-charge ratios. Some also argue that MFA would reduce costs for providers by decreasing their administrative burdens. ${ }^{13}$ Furthermore, practices might benefit from reduced time between when services are rendered and reimbursed. A current advantage of Medicare over private insurers is that Medicare often reimburses sooner.
Table 1: Fundamental objectives of the Medicare for All Acts of $2019^{2,3}$

\section{Objectives}

Establishment of a national health insurance program administered by the government that would cover all US residents

Creation of a nation health budget

Elimination of cost-sharing (deductibles, coinsurance, copayments) and balance billing for covered services

Interdiction against duplicate benefits from private health insurers or employers

Table 2: Example of neuroradiology case mix and 2019 Medicare fees compared with private insurance ${ }^{5,6 a}$

\begin{tabular}{|c|c|c|c|c|c|c|c|c|c|}
\hline Examination (CPT) & $\begin{array}{l}\text { No. of Examinations } \\
(2019)\end{array}$ & $\begin{array}{l}\text { Case Mix } \\
(\%)\end{array}$ & NR & $\begin{array}{l}\text { Medicare } \\
\text { Global }\end{array}$ & $\begin{array}{c}\text { PI } \\
\text { Global }\end{array}$ & $\begin{array}{l}\text { Medicare } \\
\text { PC }\end{array}$ & PI PC & $\begin{array}{l}\text { Medicare } \\
\text { TC }\end{array}$ & PI TC \\
\hline CT head (70450) & 44,300 & 69.5 & $\$ 0$ & $\$ 115.20$ & $\$ 369.82$ & $\$ 43.72$ & $\$ 74.54$ & $\$ 71.48$ & $\$ 295.28$ \\
\hline $\begin{array}{l}\text { CT head with contrast } \\
\text { (70460) }\end{array}$ & 50 & 0.1 & $\$ 0$ & $\$ 162.76$ & $\$ 420.63$ & $\$ 58.56$ & $\$ 95.97$ & $\$ 104.20$ & $\$ 324.66$ \\
\hline $\begin{array}{l}\text { CT head without and with } \\
\text { contrast (70470) }\end{array}$ & 564 & 0.9 & $\$ 0$ & $\$ 190.09$ & $\$ 437.57$ & $\$ 65.34$ & $\$ 106.08$ & $\$ 124.74$ & $\$ 331.49$ \\
\hline MR imaging brain (70551) & 9400 & 14.7 & $\$ 0$ & $\$ 224.92$ & $\$ 550.98$ & $\$ 76.16$ & $\$ 131.26$ & $\$ 148.77$ & $\$ 419.72$ \\
\hline $\begin{array}{l}\text { MR imaging brain with } \\
\text { contrast (70552) }\end{array}$ & 244 & 0.4 & $\$ 0$ & $\$ 311.96$ & $\$ 486.19$ & $\$ 91.71$ & $\$ 158.49$ & $\$ 220.24$ & $\$ 327.70$ \\
\hline $\begin{array}{l}\text { MR imaging brain without } \\
\text { and with contrast (70553) }\end{array}$ & 9225 & 14.5 & $\$ 0$ & $\$ 368.27$ & $\$ 911.65$ & $\$ 117.39$ & $\$ 217.90$ & $\$ 250.88$ & $\$ 693.75$ \\
\hline Total & 63,783 & 100.0 & & & & & & & \\
\hline
\end{tabular}

Note:-NR indicates nonreimbursed; PI, private insurance; TC, technical component; CPT, Current Procedural Terminology.

${ }^{a}$ Medicare fees are based on the Medicare Physician Fee Schedule database with the following criteria: year 2019 and MAC locality $0720201 .{ }^{5}$ There was no difference between Medicare facility and nonfacility fees. Private insurance fees were obtained from IBM MarketScan Commercial Claims and Encounters Database for the year 2017. Payments were adjusted for inflation using the Consumer Price Index for Medical Care obtained from the Federal Reserve Bank of St. Louis and expressed in 2019 US Ddollars. ${ }^{6}$

Table 3: Case mix and professional component fees by payer type

\begin{tabular}{clccccc}
\hline CPT & \multicolumn{1}{c}{ Examination } & Case Mix & Uninsured & Medicare $^{5}$ & Medicaid $^{\text {a }}$ & Private Insurance $^{6}$ \\
\hline 70551 & MR imaging brain WO contrast & $15 \%$ & $\$ 0$ & $\$ 74.64$ & $\$ 72.08$ & $\$ 131.26$ \\
74178 & CT Abd/pelvis WO/W contrast & $15 \%$ & $\$ 0$ & $\$ 102.53$ & $\$ 88.15$ & $\$ 173.22$ \\
76770 & US Abd complete & $10 \%$ & $\$ 0$ & $\$ 37.14$ & $\$ 32.59$ & $\$ 63.33$ \\
77067 & Screening mammogram & $20 \%$ & $\$ 0$ & $\$ 38.79$ & $\$ 37.86$ & $\$ 63.67$ \\
71046 & XR chest single & $40 \%$ & $\$ 0$ & $\$ 10.25$ & $\$ 8.52$ & $\$ 18.70$ \\
& Total & $100 \%$ & & & & \\
\hline
\end{tabular}

Note:-W indicates with; WO, without; Abd, abdomen; US, ultrasound; XR, x-ray.

${ }^{a}$ Medicaid fees represent hospital-based Medicaid PC fee averages in Louisiana for the respective examinations and were provided by the Radiology Finance Department of our lead study site. 
To illustrate the impact on reimbursement in transitioning to a single-payer system, we present in Table 3, a simplified hypothetic general radiology case mix of 5 examinations, including MR imaging of the brain. These data are based on the case mix from the primary author's radiology department and reimbursement figures for this locale to provide as realistic an example as possible of radiology reimbursement in the US multipayer system. Current Procedural Terminology codes were used to obtain volumes of the corresponding examinations performed in the first half of 2019. The finance department of the institution providing these data advised against publishing department-specific reimbursement data. With this condition, the analysis includes commonly performed examinations outside neuroradiology because high-volume studies typically make up a large proportion of overall reimbursements. Furthermore, a variety of imaging modalities more accurately reflects the impact on neuroradiologists who tend to practice in broader radiology environments.

In the general Louisiana population, approximately $13.1 \%$ of individuals are enrolled in Medicare, while about half have private health insurance. ${ }^{7}$ Typically, Medicare enrollees use more health services than privately insured individuals, which is reflected in the inpatient population payer mix (Medicare accounts for 25.8\%) derived from national data. ${ }^{14,15}$ Table 4 presents these examples of payer mixes. The payer mix of a typical radiology practice in Louisiana likely lies between these 2 examples if the practice performs both inpatient and outpatient imaging.

If we assume no change in the use of health services, if all patients in Louisiana were transitioned to Medicare at current Medicare PC fees, overall PC reimbursements for all 5 examinations in this analysis would decrease-with MR imaging of the

Table 4: Examples of payer mix

\begin{tabular}{lcc}
\hline \multicolumn{1}{c}{ Payer Type } & $\begin{array}{c}\text { Louisiana General } \\
\text { Population Payer } \\
\text { Mix }^{\mathrm{a}}\end{array}$ & $\begin{array}{c}\text { Inpatient } \\
\text { Population } \\
\text { Payer Mix }\end{array}$ \\
\hline Private insurance & $50.5 \%$ & $35.6 \%$ \\
Medicare & $13.1 \%$ & $25.8 \%$ \\
Medicaid & $28.3 \%$ & $31.9 \%$ \\
Uninsured & $8.1 \%$ & $6.7 \%$ \\
Total & $100 \%$ & $100 \%$ \\
\hline
\end{tabular}

a Based on data from the Kaiser Family Foundation 2017. ${ }^{7}$ The source data included an additional payer type "Other Public," which comprised military and the Veterans Health Administration. Our payer mix percentages were weighted to exclude this additional group, which made up $1 \%$ of the original mix.

${ }^{b}$ Derived from data from the Health Care Cost and Utilization Project and U.S. Census Bureau 2017..$^{14,15}$ brain leading that decline. The estimated revenue reduction for our simplified radiology case mix is $14 \%-20 \%$ (Table 5). Given the larger decrease for MR imaging payments, practices with higher percentages of MR imaging brain examinations could be more affected. The change in reimbursement is smaller in the inpatient scenario because Medicare and Medicaid currently make up larger proportions of payers in this setting.

\section{Considerations for Neuroradiology Practices}

The 14\%-20\% figure in Table 5 pertains to the primary author's institution and is meant to serve as an example in discussing generalizable topics under MFA. A separate study by Galvani et $\mathrm{al}^{16}$ projected a $7.4 \%$ reduction if all physician and clinical services were reimbursed at Medicare rates. For practices that own equipment, technical fees contribute largely to the total cost of an imaging study. Louisiana Medicaid does not reimburse the technical component separately but rather reimburses for an imaging examination either by full service if the provider owns the equipment or by the PC alone. ${ }^{17}$ Other states may have nuanced differences in the way Medicaid reimburses the technical component.

The size of a practice is an important determinant of reimbursement. Because larger practices tend to negotiate higher prices with private health plans than smaller practices, smaller groups may experience less drastic reimbursement decreases under MFA. There is also a smaller reduction in the inpatient payer scenario because Medicare and Medicaid make up larger proportions of payers in this setting. This is concordant with the hypothesis that practices with more privately insured patients will experience more drastic reimbursement reductions compared with those that treat a high percentage of Medicare, Medicaid, and uninsured patients. Louisiana has a high proportion of Medicaid patients and around an average proportion of uninsured patients compared with the national US averages. ${ }^{7}$ In accounting for uncompensated care and lower PC fees from Medicaid, this analysis still showed an overall decrease in PC reimbursement in a Medicare single-payer scenario. Neuroradiologists in states with higher proportions of privately insured patients may experience a more drastic impact on reimbursements under MFA.

The analysis does not factor in fluctuations in imaging volume that may occur in a single-payer system. The volume of imaging examinations would likely increase due to decreased

Table 5: Change in professional component reimbursement under Medicare for All at a radiology practice in Louisiana

\begin{tabular}{|c|c|c|c|c|c|}
\hline \multirow[b]{2}{*}{ Examination } & \multicolumn{5}{|c|}{ Payer Type Scenario } \\
\hline & $100 \%$ Medicare & $\begin{array}{c}\text { Current General } \\
\text { Population Payer Mix }\end{array}$ & \% Difference & $\begin{array}{l}\text { Current Inpatient } \\
\text { Payer Mix }\end{array}$ & \% Difference \\
\hline MR imaging brain WO contrast & $\$ 74.64$ & $\$ 96.46$ & $-23 \%$ & $\$ 89.14$ & $-16 \%$ \\
\hline $\mathrm{CT}$ Abd/pelvis WO/W contrast & $\$ 102.53$ & $\$ 125.85$ & $-19 \%$ & $\$ 117.11$ & $-12 \%$ \\
\hline US Abd complete & $\$ 37.14$ & $\$ 46.07$ & $-19 \%$ & $\$ 42.80$ & $-13 \%$ \\
\hline Screening mammogram & $\$ 38.79$ & $\$ 47.95$ & $-19 \%$ & $\$ 44.81$ & $-13 \%$ \\
\hline $\mathrm{XR}$ chest single & $\$ 10.25$ & $\$ 13.20$ & $-22 \%$ & $\$ 12.13$ & $-15 \%$ \\
\hline $\begin{array}{l}\% \text { Change if all uninsured, Medicaid, } \\
\text { and privately insured patients are } \\
\text { transitioned to Medicare }\end{array}$ & & & $-20 \%$ & & $-14 \%$ \\
\hline
\end{tabular}

Note:-W indicates with; WO, without; Abd, abdomen; US, ultrasound; XR, x-ray. 
cost-sharing for patients. ${ }^{18}$ Further research is also needed to examine realistic cost-savings opportunities (eg, administrative costs) in evaluating the overall financial impact of MFA on radiology.

The estimated decrease in PC reimbursement in this analysis is based on 2019 Medicare PC fees. The Medicare Physician Fee Schedule for 2020 entailed cuts in reimbursement for radiology to boost reimbursement for care-related evaluation and management services. It is estimated this change will cost radiologists $\$ 450$ million in 1 year alone, and $\$ 5.6$ billion during the next decade. ${ }^{19}$ We also note that with reimbursement changes following passages of the Patient Protection and Affordable Care Act and Medicare Access and CHIP Reauthorization Act of 2015, it is also possible that fee-for-service may be substantially or completely replaced by alternative payment models (eg, bundled or episodebased payments, capitated payments, global budgets, and government salaried providers). ${ }^{13}$

\section{Is Medicare for All Better for Our Patients?}

Compared with patients in other high-income countries, Americans are more likely to report financial barriers to health care, ${ }^{20,21}$ with a third of US adults reporting difficulty paying medical bills in $2018 .^{22}$ This situation is often sensationalized in the media, creating a perception that the US health care industry takes advantage of sick people. Such a belief can undermine public trust in our health care system. Below, we discuss concerns commonly brought up by American patients and concerns regarding MFA.

In 2018, approximately 30.4 million persons in the United States were uninsured. ${ }^{23}$ MFA would certainly extend coverage to more patients, and proponents of this system argue that increasing access to preventative care will reduce overall health care costs (eg, by decreasing emergency department use or hospital admissions for acute exacerbations of chronic illnesses). Prior research found that extending Medicaid coverage resulted in more health care use, including emergency department visits, without immediate improvement in health measures such as blood pressure or cardiovascular risk. It did, however, reduce the prevalence of depression and medical debt. ${ }^{24}$

In addition to expanding coverage, proponents argue that MFA would provide more stable coverage. Currently, many Americans receive health insurance through their employers, and changing jobs can result in coverage fluctuations. MFA does not address how the government would feasibly absorb this cost from employers and risks encountering similar issues as other countries if unprepared. Several countries with highly regarded universal health care systems now struggle to finance their health care systems. Since 2010, the National Health Service budget of the United Kingdom has fallen short of its health care costs, resulting in longer wait times for patients, reduced payments to providers, and calls for tax increases. ${ }^{25-27}$ Canada and Australia have faced similar issues of unsustainable rising health care costs, with consequent restrictions on services and increased reliance on private insurance. ${ }^{28,29}$

The above is not a critique of the principle of universal health insurance but rather of how health care costs have become unsustainable despite a variety of coverage designs. In reforming health care, current politics seems to focus more on who will pay for care rather than on strategies and resources to promote healthier lifestyles. Modern challenges, such as increases in the prevalence of chronic diseases, risk overwhelming the health care system. Although MFA aims to increase access to care, any such legislation will likely have a minimal effect on the root causes of contemporary issues such as sedentary lifestyles and poor diet. While we have focused mainly on financial implications, we acknowledge that there are innumerable other factors to consider in evaluating health care systems.

In summary, implementation of a single-payer system might solve some problems but would likely introduce several others. As key stakeholders in health care, neuroradiologists should scrutinize how emerging legislation will affect their practices and patients.

Disclosures: Richard Duszak—RELATED: Grant: Harvey L. Neiman Health Policy Institute.* Michal Horný—RELATED: Grant: Harvey L. Neiman Health Policy Institute.* Joshua A. Hirsch-UNRELATED: Consultancy: Medtronic, Relievent, Comments: Medtronic consultant, Relievant Data-Monitoring Committee; Grants/Grants Pending: Harvey L. Neiman Health Policy Institute. *Money paid to the institution.

\section{REFERENCES}

1. Public Opinion on Single-Payer, National Health Plans, and Expanding Access to Medicare Coverage. KFF. February 21, 2019. https://www.kff.org/slideshow/public-opinion-on-single-payer-nationalhealth-plans-and-expanding-access-to-medicare-coverage/. Accessed June 11, 2011

2. Medicare for All Act of 2019. S.S. 1129 from 116th Congress. B. Sanders, Author. https://www.congress.gov/116/bills/s1129/BILLS116s1129is.pdf. Accessed May 10, 2019

3. Medicare for All Act of 2019, H.R. 1384 from 116th Congress. J. Pramila, Author. https://www.congress.gov/bill/116th-congress/ house-bill/1384. Accessed May 10, 2019

4. Uhrmacher K, Schaul K, Firozi P, et al. Where 2020 Democrats stand on Medicare-for-all. The Washington Post. March 5, 2019. https://www.washingtonpost.com/graphics/politics/policy-2020/ medicare-for-all/. Accessed August 17, 2019

5. U.S. Centers for Medicare \& Medicaid Services. 2019. Physician Fee Schedule Search. https://www.cms.gov/apps/physician-fee-schedule/ search/search-criteria.aspx. Accessed November 1, 2019

6. Federal Reserve Bank of St. Louis, U.S. Bureau of Labor Statistics. Consumer Price Index for All Urban Consumers: Medical Care in U.S. City Average. February 2020. https://fred.stlouisfed.org/ series/CPIMEDSL. Accessed February 10, 2020

7. Kaiser Family Foundation. Health Insurance Coverage of the Total Population. 2008-2018 https://www.kff.org/other/state-indicator/ total-population $/$ ? currentTimeframe $=0$ \&sortModel $=\% 7 \mathrm{~B} \% 22$ colld \%22:\%22Location\%22,\%22sort\%22:\%22asc\%22\%7D. Accessed July 9, 2019

8. Congressional Budget Office. An Analysis of Private-Sector Prices for Physicians' Services: Working Paper 2018-01. United States. January 12, 2018. https://www.cbo.gov/publication/53441. Accessed June 11, 2019

9. Maeda JM, Marder WD, Karaca Z, et al. Variation in hospital inpatient prices across small geographic areas. Am J Manag Care 2014;20:907-16 Medline

10. Hargraves J, Biniek J; Health Care Cost Institute. Comparing Commercial and Medicare Rates for Select Anesthesia ER, and Radiology Services by State. July 23, 2019. https://health costinstitute.org/out-of-network-billing/median-allowed-amountsesi-2017. Accessed September 17, 2019

11. Zuckerman Skopec L, Epstein M, et al. Urban Institute. Medicaid Physician Fees after the ACA Primary Care Fee Bump. March 2017.https://www.urban.org/sites/default/files/publication/88836/ 
2001180-medicaid-physician-fees-after-the-aca-primary-care-feebump_0.pdf. Accessed September 17, 2019

12. Medicaid-to-Medicare Fee Index; State Health Facts. 2016. https:// www.kff.org/medicaid/state-indicator/medicaid-to-medicare-fee-index/ ?currentTimeframe $=0$ \&selectedRows $=\% 7 \mathrm{~B} \% 22$ wrapups $\% 22: \% 7 \mathrm{~B}$ \%22united-states\%22:\%7B\%7D\%7D\%7D\&sortModel=\%7B\%22colId \%22:\%22Location\%22,\%22sort\%22:\%22asc\%22\%7D. Accessed August 15,2019

13. Congressional Budget Office. Key Design Components and Considerations for Establishing a Single-Payer Health Care System. May 2019. https://www.cbo.gov/system/files/2019-05/ 55150-singlepayer.pdf. Accessed June 11, 2019

14. Sun RA, Karaca Z, Wong HS. Trends in Hospital Inpatient Stays by Age and Payer. 2000-2015. H'CUP Statistical Brief. January 2018. www.hcup-us.ahrq.gov/reports/statbriefs/sb235-InpatientStays-Age-PayerTrends.pdf. Accessed October 20, 2019

15. Health Insurance Coverage Status and Type of Coverage by Selected Characteristics. 2017. United States Census Bureau. https:// www.census.gov/data/tables/. Accessed November 5, 2019

16. Galvani AP, Parpia AS, Foster EM, et al. Improving the prognosis of health care in the USA. Lancet 2020;395:524-33 CrossRef Medline

17. Louisiana Department of Health. Professional services provider manual. Chapter Five of the Medicaid Services Manual. https:// www.lamedicaid.com/provweb1/Providermanuals/manuals/PS/PS. pdf. Accessed January 3, 2020

18. Manning WG, Newhouse JP, Duan N, et al. Health Insurance and the Demand for Medical Care: Evidence from a Randomized Experiment. In: Manning WG, Newhouse JP, Duan N, et al. RAND Report. RAND Corporation: 1988

19. Stempniak M. ACR disappointed as feds finalize policy that could cost field billions. RADIOLOGY BUSINESS. November 4, 2019. https://www.radiologybusiness.com/topics/policy/american-collegeradiology-cms-physician-fee-schedule. Accessed November 10, 2019

20. Osborn R, Squires D, Doty MM, et al. New survey of eleven countries, US adults still struggle with access to and affordability of health care. Health Aff (Millwood) 2016;35:2327-36 CrossRef Medline
21. 2016 Commonwealth Fund International Health Policy Survey of Adults. March-June 2016. https://www.commonwealthfund. org/publications/surveys/2016/nov/2016-commonwealth-fundinternational-health-policy-survey-adults. Accessed June 17, 2019

22. Collins SR, Bhupal HK, Doty M. Health Insurance Coverage Eight Years After the ACA: Fewer Uninsured Americans and Shorter Coverage Gaps, But More Underinsured. Commonwealth Fund, February 2019. Accessed June 4, 2019

23. Cohen RA, Terlizzi EP, Martinez ME. Health insurance coverage: early release of estimates from the National Health Interview Survey, 2018. National Center for Health Statistics. May 2019. https://www.cdc.gov/nchs/data/nhis/earlyrelease/insur201905.pdf. Accessed June 17, 2019

24. Baicker K, Allen HL, Wright BJ, et al. The effect of Medicaid on medication use among poor adults: evidence from Oregon. Health Aff (Millwood) 2017;36:2110-14 CrossRef Medline

25. Martinson ML, Teitler JO, Reichman NE. Health across the life span in the United States and England. Am J Epidemiol 2011;173:858-65 CrossRef Medline

26. Torjesen I. Taxes must rise to fund $5 \%$ budget increase the NHS needs. BMJ 2018;361:k2337 CrossRef Medline

27. Financial sustainability of the NHS. Report by the Comptroller and Auditor General of The National Audit Office. Presented to the House of Commons 785 Session. 2016-17. November 22, 2016. https://www.nao.org.uk/wp-content/uploads/2016/11/FinancialSustainability-of-the-NHS.pdf. Accessed August 18, 2019

28. Barua B, Palacios M, Emes J. The Sustainability of Health Care Spending in Canada 2017. Fraser Institute. https://www.fraser institute.org/sites/default/files/sustainability-of-health-care-spending-incanada-2017-execsum.pdf. Accessed June 3, 2019

29. Stoelwinder J. Sustaining universal health care in Australia: Introducing dynamic efficiency. CEDA, Healthcare: Reform or Ration. https://www.ceda.com.au/CEDA/media/ResearchCatalogue Documents/PDFs/15366-healthcarefinall.pdf. Accessed June 3, 2019 